\title{
O corpo no Ocidente Medieval
}

\section{Uma história do corpo na ldade Média.}

LE GOFF, Jacques; TRUONG, Nicolas. Tradução: Marcos Flamínio Pires. Revisão técnica: Marcos de Castro.

Rio de Janeiro: Civilização Brasileira, 2006. 207 p.

O corpo está no centro de toda relação de poder. Mas o corpo das mulheres é o centro, de maneira imediata e específica. ${ }^{1}$
Desse modo, Michelle Perrot, em 1994, sintetizava as relações de poder que mediavam estreitamente os debates sobre 'gênero' na Europa. Muito embora Jacques Le Goff apenas circunstancialmente houvesse tratado do assunto, com Uma história do corpo na ldade Média, que foi escrito em parceria com Nicolas Truong, os autores ofereceram uma bela contribuição para o entendimento desse tema na Civilização do Ocidente Medieval.

Não faz muito tempo que os estudos históricos se abriram para um conjunto de temas e objetos mais amplo, o que, mesmo assim, não quer dizer que todos os temas, fontes e objetos já foram pesquisados pelo historiador. Quanto maior é o número de abordagens possíveis de serem utilizadas na pesquisa histórica, mais nítida se torna a constatação de que as 'grandes' 
mudanças teóricas e metodológicas da história são provenientes da renovação e da ampliação dos temas investigados.

No entanto, o problema, muitas vezes, está em operacionalizar adequadamente um procedimento de pesquisa à análise de certos objetos. Cada vez mais tem se demonstrado que certos problemas, certas abordagens são pertinentes para alguns temas, mas não para outros. Como tornar o assunto passível de ser inquirido e estudado pelo pesquisador é, nesse caso, o problema fundamental. E foi pensando nessas questões que os autores indicam a necessidade de estudarem o 'corpo' na Idade Média europeia e justificam esse propósito.

Desde o início a preocupação dos autores esteve em demonstrar que o corpo, enquanto objeto de pesquisa, constitui uma das grandes lacunas da história, "um grande esquecimento do historiador. A história tradicional era, de fato, desencarnada. Interessava-se pelos homens e, secundariamente, pelas mulheres. Mas quase sempre sem corpo" (p. 9). Pensando nisso, seria, segundo eles, "preciso [...] dar corpo à história. E dar uma história ao corpo" [porque] "o corpo tem uma história", [e a] "concepção do corpo, seu lugar na sociedade, sua presença no imaginário e na realidade, na vida cotidiana e nos momentos excepcionais sofreram modificações em todas as sociedades históricas" (p. 10). Por isso mesmo, a "história do corpo na ldade Média é [...] uma parte essencial de sua história global" (p. 11), inevitável e indispensável para se compreender adequadamente a sociedade contemporânea, na qual o corpo tem, progressivamente, ganhado cada vez mais destaque na mídia.

Mas, tratando-se de um tema pouco estudado, embora justificável de tal esforço, como deve ser estudado o corpo na história das sociedades? Como o corpo foi pensado e visualizado na Idade Média? O que foi, portanto, o 'corpo' para aquela sociedade do Ocidente Medieval?

Para eles, primeiro, o corpo foi o resultado de uma das várias tensões vividas no período, porque a "dinâmica da sociedade e da civilização medievais resulta[va] de tensões" (p. 11). E uma das principais tensões no período "é aquela entre o corpo e a alma". De um lado, o corpo é fruto da benção e da glorificação, principalmente religiosa (quando se trata do corpo de Cristo), e, de outro, é "desprezado, condenado, humilhado". Isso porque "O corpo cristão medieval é de parte a parte atravessado por essa tensão, esse vaivém, essa oscilação entre a repressão e a exaltação, a humilhação e a veneração" (p. 13). Segundo, e como consequência, as representações dos homens sobre as mulheres, e sobre eles mesmos no período (que tinha na visão sua principal medida de sentido da realidade), acabavam sendo mediadas por aquelas 'tensões' entre o material e o espiritual. Terceiro, para melhor compreender o período, os autores pensaram a ldade Média na sua divisão clássica dos séculos $V$ ao $X V$ e, também, entre os séculos XV e XVIII, cujas principais características, eles acreditam, ainda estejam incidindo sobre a sociedade ocidental.

Portanto, dos questionamentos acima, o mais difícil para os autores foi como estudar o corpo, objeto praticamente "esquecido pela história e pelos historiadores", segundo apontam, ao longo da justificativa desse trabalho. Para eles, autores como Norbert Elias, Marc Bloch, Lucien Febvre, Michel Foucault, e mesmo Jules Michelet no século XIX, foram exceções àquela regra, abrindo caminhos, que depois foram prosseguidos por Ernest H. Kantorowicz (1895-1968), Mikhail Bakhtin (1895-1975), Michel de Certeau (19251986), Georges Duby (1919-1996), Paul Veyne, Peter Brown e Jean-Claude Schmitt. Os autores indicam ainda a importância dos estudos sociológicos (desde os produzidos por Émile Durkheim) e dos antropológicos (desde os pioneiros do século XIX). Ao demonstrarem sua dívida intelectual para com esses autores pioneiros, eles apontam que, ainda assim, o corpo continuou um objeto pouco estudado. Desse modo, o corpo ser investigado na ldade Média era também oportuno, não apenas por ser escassamente estudado, mas porque naquele período se concebeu muitos de nossos comportamentos. Com o 'cristianismo' houve uma reestruturação nos conceitos e nas práticas corporais e comportamentais daquela sociedade. Foi o momento de formação do 'Estado' e das 'cidades modernas', "de que o corpo será uma das mais prolíficas metáforas e cujas instituições o irão moldar". No plano cultural houve uma completa alteração no espaço urbano, que acabou redefinindo as próprias práticas religiosas, ao redimensionar o centro de poder do 'campo' para as 'cidades'. Na ldade Média, "o corpo é o lugar crucial de uma das tensões geradoras da dinâmica do Ocidente" (p. 31), porque até então era uma novidade. Por outro lado, pensar o corpo e a sua história é pertinente também para se inquirir a sociedade contemporânea e a sua revolução comportamental, sexual, gestual e corporal, acelerada a partir dos anos de 1960.

Para delimitarem melhor a pesquisa, os autores dividiram o trabalho em quatro capítulos. 
Os dois primeiros, mais densos e consistentes, abrangem 98 páginas ( 56 p. e 42 p.) e discutem as consequências do carnaval e da quaresma, e de viver e morrer na Idade Média. Os dois últimos, com 42 páginas ( 22 p. e 20 p.), discutem como o corpo passou a ser sistematicamente 'civilizado' e utilizado como uma 'metáfora' para se pensar outras questões e lugares.

Para eles,

A humanidade cristã repousa tanto sobre o pecado original - quanto sobre a encarnação: Cristo se faz homem para redimir os homens de seus pecados. Nas práticas populares, o corpo é contido pela ideologia anticorporal do cristianismo institucionalizado, mas resiste à sua repressão (p. 35).

A 'tensão' entre um corpo feminino 'diabolizado' e um corpo masculino 'endeusado' ficaria latente no período, porque de início o corpo na ldade Média foi renunciado. Controlar a sexualidade feminina, seus gestos, suas práticas, sua conduta na sociedade passaria a ser uma questão mediada pela Igreja e aceita pela sociedade. Mesmo assim, o próprio corpo feminino não deixou de também ter 'tensões' entre o bem (a procriação, a virgindade de 'Maria', a castidade e o cuidado com a família) e o mal (a sexualidade, a prostituição, a luxúria e a perversão da alma), porque "o culto do corpo da Antiguidade cede lugar, na ldade Média, a uma derrocada do corpo na vida social" (p. 37). Igualmente importante, foram os 'tabus' construídos pela instituição religiosa sobre os fluidos corporais, como o esperma e o sangue. E "é possível afirmar que o corpo sexuado da ldade Média é majoritariamente desvalorizado, as pulsões e o desejo carnal, amplamente reprimidos" (p. 41), principalmente, no discurso institucionalizado da Igreja:

[...] a religião cristã institucionalizada introduz uma grande novidade no Ocidente: a transformação do pecado original em pecado sexual. Uma mudança que é uma novidade para o próprio cristianismo, já que, em seus primórdios, não aparece traço algum de uma tal equivalência, assim como nenhum termo dessa equação figura no Antigo Testamento da Bíblia. O pecado original, que expulsa Adão e Eva do Paraíso, é um pecado de curiosidade e de orgulho (p. 49).

No entanto,

A transformação do pecado original em pecado sexual é tornada possível por meio de um sistema medieval dominado pelo pensamento simbólico. Os textos da Bíblia, ricos e poliva- lentes, se prestam de bom grado a interpretações e deformações de todos os gêneros. A interpretação tradicional afirma que Adão e Eva quiseram encontrar na maçã a substância que lhes permitiria adquirir uma parte do saber divino. Já que era mais fácil convencer o bom povo de que a ingestão da maçã decorria da copulação mais que do conhecimento, a oscilação ideológica e interpretativa instalouse sem grandes dificuldades (p. 51).

Assim, não é por acaso que "a subordinação da mulher possui uma raiz espiritual, mas também corporal". Sendo ela 'fraca', conforme a verá a lgreja, "a primeira versão da Criação presente na Bíblia é esquecida em proveito da segunda, mais desfavorável à mulher". Com isso, da "criação dos corpos nasce, portanto, a desigualdade original da mulher", e ela "irá pagar em sua carne o passe de mágica dos teólogos, que transformaram $\circ$ pecado original em pecado sexual". Por outro lado, "ela é subtraída até mesmo em sua natureza biológica, já que a incultura científica da época ignora a existência da ovulação, atribuindo a fecundação apenas ao sexo masculino" (p. 54). Não foi sem razão que Georges Duby disse que essa ldade Média é "masculina", pois todos os discursos que nos chegaram, além de serem escritos por homens, estes estavam convictos de sua superioridade, como lembrarão ainda os autores.

De acordo com os autores, a revanche do 'corpo' martirizado pela Quaresma, que visava contornar o 'paganismo' e sistematizar regras de conduta para homens e, principalmente, para as mulheres, estava nas práticas do Carnaval. A tensão entre a Quaresma e o Carnaval será também uma tensão entre a vontade e a liberação, a regra e a discórdia, o bem e o mal, o homem e a mulher, numa sociedade fundamentalmente rural (já que em torno de $90 \%$ da população vivia nos campos nesse período). As cidades só passaram a ter maior representatividade entre os séculos XII e XIV. Numa tensão semelhante estará o 'trabalho', entre o castigo e a criação. Vê-se ainda que

O corpo é separado entre as partes nobres (a cabeça, o coração) e ignóbeis (o ventre, as mãos, o sexo). Ele dispõe de filtros que podem servir para distinguir o bem do mal: olhos, orelhas e boca.

A cabeça está do lado do espírito; o ventre, do lado da carne. Ora, o riso vem do ventre, isto é, de uma parte má do corpo [não sendo, por isso, visto com bons olhos pelos teólogos e, consequentemente, pela sociedade] (p. 76). 
Assim, o "Carnaval do coração se manifesta[va] sob a Quaresma do corpo. [...] O que não quer dizer que os homens e as mulheres da Idade Média não conheçam os arroubos do coração ou as folias do corpo, que ignorem o prazer carnal e a afeição pelo ser amado, mas o amor, sentimento moderno, não era um fundamento da sociedade medieval" (p. 97). $O$ desinteresse pela mulher na ldade Média dá-se também no período de gestação, em que a mulher grávida "não é objeto de nenhuma atenção particular". E essa desatenção perpassa sobre todas as camadas da sociedade. $\mathrm{Na}$ velhice, a mulher também não será bem quista, em muitas ocasiões, por ser, dependendo de sua conduta, vista como 'bruxa'. De modo geral, a velhice feminina terá uma desatenção semeIhante à da mulher grávida.

As doenças e o estado mental das pessoas durante esse período também sofrerão altos e baixos, vindo a ser ora motivo de aversão, ora de cuidados e de arrependimento. Mais ainda,

[...] os homens da ldade Média podem recorrer a um outro médico além de Cristo. Pouco a pouco, os médicos da alma - os padres - se distinguem daqueles do corpo - os médicos , que vão se tornar ao mesmo tempo sábios e profissionais, assim como uma corporação, um corpo de ofício. Surgem escolas de medicina, assim como universidades em que homens se formam em uma ciência que é considerada, sem dúvida, um dom de Deus, mas, igualmente, um ofício. Os médicos trabalham, pois, como profissionais pagos [...] (p. 113).

As 'tensões' da ldade Média, por isso mesmo, não se limitavam apenas às questões corporais, mas estavam, inevitavelmente, ligadas a questões espirituais. $O$ trato dos vivos com os mortos é um exemplo singular:

Desde a Antiguidade, com efeito, os vivos se ocuparam dos corpos dos membros de suas famílias. As mulheres, em particular, eram encarregadas de lavá-los, de prepará-los para juntarem-se ao reino dos mortos que, segundo a crença, retornavam às vezes para atormentar a alma dos vivos. Com o cristianismo, estabelece-se uma hierarquia entre os defuntos, sem colocar em questão as práticas herdadas do paganismo. Somente as sepulturas dos santos, danificadas e manipuladas de diferentes maneiras, podiam ser objeto de celebração e veneração. Reza-se para os mortos, é certo, mas com a intercessão de novos heróis, os santos (p. 122).

É a conduta dos 'vivos' que mediará os seus destinos após a 'morte'. Aos que se compor- taram adequadamente, o 'Paraíso'; aqueles que não, o 'Inferno'. Esse era o tipo de 'horizonte' que invadia o pensamento dos homens e das mulheres da Idade Média.

A dieta alimentar, o respeito às regras, o cultivo do espírito e a submissão à Igreja marcavam, assim, as expectativas dos homens e das mulheres. Desse modo, o cuidado com o nu, com os excessos de alimentos, a 'gula', com as práticas corporais (o sexo, em particular) e esportivas (a mostra do corpo em público), igualmente, marcavam o tipo de conduta a ser respeitada. Durante a Idade Média, as normas quanto às condutas corporais não se limitavam apenas aos membros da sociedade, como ainda faziam parte da própria organização das metáforas usadas para definir o espaço de convivência social, em especial, o das cidades:

As concepções organicistas das sociedades fundadas sobre metáforas corporais que utilizam ao mesmo tempo partes do corpo e o funcionamento do corpo humano ou animal em seu conjunto remontam à alta Antiguidade. [...] O sistema cristão de metáforas corporais repousa sobretudo no binômio cabeça/ coração. O que dá toda força a essas metáforas nesse sistema é o fato de que a Igreja, sendo comunidade de fiéis, é considerada um corpo do qual Cristo é a cabeça. Essa concepção dos fiéis como semelhantes a membros múltiplos, levados por Cristo à unidade de um só corpo, foi estabelecida por São Paulo (p. 162).

Nessa medida, a metáfora corporal também será igualmente importante na definição da organização das cidades e da realeza, das funções do rei e de sua mediação entre a matéria e o espírito. Portanto,

\begin{abstract}
A história do corpo oferece ao historiador e ao interessado em história uma vantagem, um interesse suplementar. $O$ corpo ilustra $e$ alimenta uma história lenta. A essa história lenta, que é, em profundidade, a das idéias, das mentalidades, das instituições e mesmo a das técnicas e das economias, esse interesse dá um corpo, o corpo (p. 173).
\end{abstract}

Nesse sentido, o "corpo tem, portanto, uma história", o corpo foi o tema dessa história escrita pelos autores. Resumido o enredo principal do livro, convém que se analisem alguns pontos. Primeiro, embora partam do suposto de que a abordagem cubra o período do século $\mathrm{V}$ ao XVIII, a interpretação privilegia os séculos $X$ ao XIV. Segundo, por ser uma obra de caráter de síntese (tal como o ensaio), e não monográfico, nem por isso deixa de ser oportuna a obser- 
vação sobre o uso demasiado das generalizações, quanto aos comportamentos femininos e masculinos para o período, sobre a maneira de controlar as vontades humanas por intermédio de um sistema de regras de conduta (elaborado e organizado pela Igreja) e sobre as formas de representação dos corpos para toda a sociedade europeia na Idade Média. Destaque-se ainda que, mesmo sendo um tema pouco explorado pela historiografia ocidental, a história do corpo mostra-se um tema rico, e ainda mais complexo do que supuseram os próprios autores, mesmo quanto ao que concerne ao período da ldade Média. ${ }^{2}$ Deixando de lado as reservas, não há como negar os méritos e as contribuições dessa obra, principalmente, por destacar as 'metamorfoses', positivas e negativas, sobre as representações do corpo feminino e masculino, e suas tensões entre o material e o espiritual na Civilização do Ocidente Medieval.

\section{Notas}

1 Michelle PERROT, 2005, p. 447.

2 Jean-Claude SCHMITT, 2007; e Alain CORBIN, Georges VIGARELLO e Jean-Jacques COURTINE, 2008.

\section{Referências bibliográficas}

CORBIN, Alain; VIGARELLO, Georges; COURTINE, Jean-Jacques (Orgs.). História do corpo. Petrópolis, RJ: Vozes, 2008. 3 v.

PERROT, Michelle. As mulheres ou os silêncios da história. Tradução: Viviane Ribeiro. Bauru, SP: Edusc, 2005.

SCHMITT, Jean-Claude. O corpo das imagens. Ensaios sobre a cultura visual na ldade Média. Bauru, SP: Edusc, 2007.

Diogo da Silva Roiz Universidade Estadual de Mato Grosso do 